\title{
THE NEW NEUROCOGNITIVE SCIENCE OF LANGUAGE: INNOVATIVE EXPERIMENTAL DESIGN FOR STUDYING SYNTACTIC AND SEMANTIC PROCESSING IN COMMUNICATIVE SETTINGS, AN INTERVIEW WITH KATRIEN SEGAERTS
}

Ana Regina Calindro ${ }^{1}$ Marije Soto ${ }^{2}$
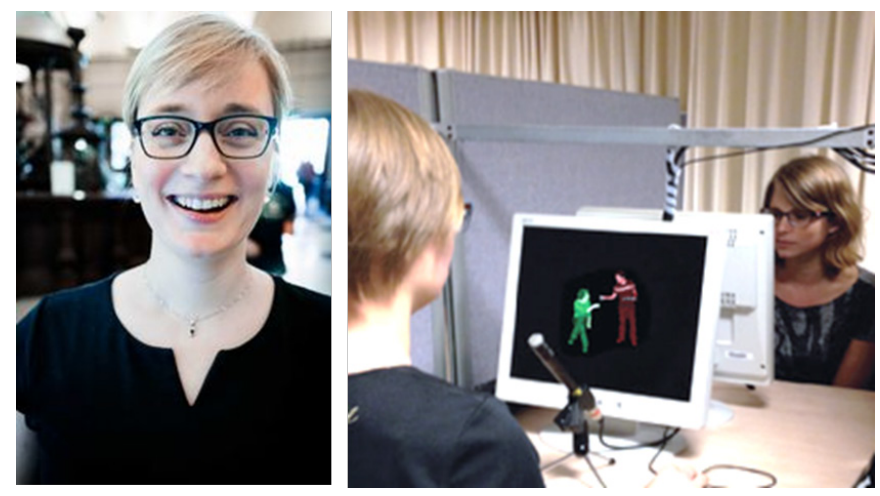

Katrien Segaert is the head of the Neuroscience of Language lab at the School of Psychology at the University of Birmingham (UK), where she is also affiliated with the Centre for Human Brain Health. Her research deals with the major question of how syntax and semantic processing are instantiated in the brain within the context of communicative settings, and how the neurobiological circuitry for sentence processing changes throughout our lives. Her lab does experimental studies with a variety of techniques, ranging from EEG and fMRI to classical psycholinguistic methodologies. Her work has been really innovative in the ways she has managed to bring communicative context to experimental paradigms: participants engaged with avatars, or interacted with interlocutors while lying in the MRI scanner. Another series of her studies that have attracted some media attention are those involving aging adults: results have shown surprising correlations between language processing and fitness. She has agreed to talk to us about working with novel experimental methodologies in a

1 Profa. Adjunta do Departamento de Linguística e Filologia, Faculdade de Letras, Universidade Federal do Rio de Janeiro; membro do Programa da Pós-graduação em Linguística, Universidade Federal do Rio de Janeiro; email: anacalindro@letras.ufrj.br.

2 Profa. Adjunta do Departamento de Estudos da Linguagem, Instituto de Letras, Universidade do Estado do Rio de Janeiro; membro do Programa da Pós-graduação em Linguística, Universidade Federal do Rio de Janeiro; email: marijesoto@hotmail.com . 
highly interdisciplinary field.

A/M: Because you work in an interdisciplinary field, perhaps your research is not that well known to people who work with more traditional linguistics. So, could you describe for those that may not be so familiar with cognitive neuroscience and psycholinguistics, what it is that you do?

K: I look at language not from a linguistic perspective, it's a psycholinguistic perspective. So it's all about behavior. It's how people behave, how they produce and comprehend language. For example - if we're talking about syntax - which syntactic structure do they produce, how fast do they produce it, are they influenced by the structure they just heard? It's always an empirical question. Then I try to relate that to theory, in a sense that you wonder, what does the data you have tell you about theories? For example, how is this syntactic information represented in our cognitive space or in the brain?

$\mathrm{A} / \mathrm{M}$ : What is your view on the nature of language? This goes perhaps a little bit more back to theories, and how it affects the way you choose subject matters, methodologies?

K: It sounds strange talking to two linguists, but I don't think I am ever led, in terms of my research question, by a theory. I suppose I am always driven by something I want to know, and it's about knowing if is this correct or not? The starting point is always an empirical question, indirectly, it is driven by theory, because, of course, there are previous people who have thought about these questions. But the theory itself is not the starting point. The starting point is something we don't know yet, because there's more than one theory, or the theories aren't specified enough. I also don't feel tied to a specific method ever. I just have a question and I try to figure out what the best method to answer it would be. It could be a very simple behavioral experiment or a super complicated fMRI experiment. It doesn't matter as long as it answers the question.

A/M: Can you give an example? Maybe something to illustrate it?

$\mathrm{K}$ : One line of research that I did quite a lot of experiments on, was about syntactic processing: how we put the building blocks together when we're comprehending language, versus when were producing language. There are a lot of theories about how we do this in comprehension and there are a lot of theories about how we do this in production. I started from scratch. I thought we need to think about how we do this when we're listening to language versus when we're speaking. Maybe there's more shared than there are differences, so maybe the starting point of all of it is wrong. Then I did a bunch of experiments to see if there is something shared in the brain when you're engaging 
in syntactic processing. It turned out that you had all the exact same brain regions, the exact same network of brain regions, working together to do syntactic processing irrespective of whether you were listening or speaking. ${ }^{3}$ So if I had started out from a specific theory and tested a theory, I would have never gotten there.

A/M: On the other hand, I know people who are not at all interested in looking at syntax, for example. So, your view of the nature of language obviously did lead you to that point, because there are people who never feel like investigating syntax. Maybe you can tell us a little bit about that.

$\mathrm{K}$ : Yes, that is true and I definitely don't want to say that you should never start from a theory. Even if you don't start from a theory, you always have to get to a point where you reflect on how your findings are relevant for the theories that we have. You always have to link to theory, but I suppose it could be at the start or at the end, or at both.

A/M: For example, why are you interested in syntax as opposed to pragmatics or semantics?

K: [Syntax], I think, was a logical starting point when I was a graduate student. Now, I am starting to try and see the similarities also between what you're doing on a meaning level versus what you're doing on a syntactic level, and there are so many things that are similar. You have these building blocks you have to put together, then you put them together in a way that you are doing a lot more than just putting them next to each other, you'll have to do some sort of process where you're doing much more than just adding them. In my opinion there's a lot there that could be similar for the two [syntax and semantics], as well in terms of how this works in the brain and how this is implemented. The boundaries are very fluid.

$\mathrm{A} / \mathrm{M}$ : Where does your interest in syntactic priming come from?

$\mathrm{K}$ : I'm not sure. I was a master student and I was doing my masters in psychology in Belgium and there weren't really any psycholinguists in the psychology department. and I just thought 'ooh, this might be interesting'. It was only afterwards when I was a graduate student, and I learned much more about it [priming paradigm] that I really understood how powerful this can be, because you can learn so much about how things are represented in your cognitive space, but also in the brain. It's such a useful tool if you're doing neuroimaging research because it allows so much control. It's a really helpful design if you are a neuroimaging person, but I didn't understand that until much later.

3 Segaert, K., Menenti, L., Weber, K., Petersson, K. M., \& Hagoort, P. (2012). Shared syntax in language production and language comprehension — An fMRI study. Cerebral Cortex, 22, 1662-1670. doi:10.1093/cercor/bhr249. (the article can be accessed here: https://pure.mpg.de/rest/items/item_979636_14/component/file_1481364/content ). 
A/M: Is your background in psychology?

K: I'm not a linguist at all. I feel very nervous talking to linguists because of it, because there are so many things I don't understand.

$\mathrm{A} / \mathrm{M}:$ And vice versa!

A/M: A lot of your papers are innovative in that you try to bring communicative settings into experimental paradigms. How do you feel about the challenges of this endeavor, and what constitutes a valid communicative setting minimally?

$\mathrm{K}$ : I guess a minimal communicative setting is when there is a message that's exchanged between two interlocutors, successfully or not successfully. You have a speaker, who has a message in mind, then needs to perform all these processes to get some sort of motor output and speech. Then you have a listener, all of that [which was produced by the speaker] reaches their auditory cortex, they have to do all of these processes, and verify if this is the message that the speaker intended. Well this is a very narrow view on what communication is. Of course, there's sign language, so you could have two signers. Maybe you don’t even need two people, it could be a writer and a reader...

$\mathrm{A} / \mathrm{M}$ : The reason I'm asking this is because there are some linguists who claim we can only investigate language in a highly contextualized setting. What is your view on that?

K: Some of us need to. I don't know if every one of us need to, because there are a lot of questions you can answer when you don't [investigate in a communicative contextualized setting]. But at least some of us need to because we know that languages process differently in a communicative setting versus when there isn't one. I mean you can answer all sorts of super nitpicky questions about how language works, but at some point you have to connect it back to everything around it, because they influence each other. You know that you are going to communicate differently with different people, and that those things matter. It matters if people have aligned with each other previously, whether they've shared information previously, whether there is a social context, what the social context is. Maybe you have a teacher and a student, or two friends, or a husband and a wife. If the husband and the wife just had a fight or not, or if they are having a super good day with each other. You can have someone you love, someone that you don't get along with at all, someone who has a lot of empathy, someone that doesn't. All of those things are going to influence how you produce and how you comprehend language. It's not an isolated process that is completely modular and separate from all of those other things, and, of course, there are a lot of things we need to learn within this module of 
language, but at some point some language researchers need to start thinking about how all of these things around it influence language processing.

A/M: We saw in your research that communicative setting is important. How do you emulate real communicative situations in an experimental environment?

$\mathrm{K}$ : It's horrible, really difficult, because you can try in so many different ways to make it more naturalistic, but it will never be. Unless you start studying something like this [referring to the actual conversation between interviewers and interviewee], but then you lose experimental control. So you always have to balance the two, and I suppose it depends on your research question how you end up balancing the two.

A/M: Do you think it is valid to compare an experiment, when you have a controlled environment, to a certain real situation that has been recorded, for example?

$\mathrm{K}$ : It depends on the research question. Because when you're emulating something that's real, there are so many things that come into play, and, if you add a thousand confounding variables, what have you learned? You still don't really know what you're studying. So you have to then try and add them one by one, but then that's not naturalistic either because you know you're adding them one by one. So it's a really difficult thing to do and we've tried in different ways to make progress with it, and we've learned that it's just really difficult.

A/M: Is it important that it's comparable? Because, as you said, sometimes a very abstract experiment can have a great explanatory power. How do you feel about that? In regards to your research questions, how successful has it been?

$\mathrm{K}$ : It takes a lot of experience. It's not something that you get right the first time. We've tried it in many different ways. Simply inviting two participants in the lab and doing a task together. Inviting a participant and a confederate into the lab, where the confederate is a research assistant. We've done it in a virtual reality, where you are interacting with a virtual agent. We've done fMRI experiments ${ }^{4}$

4 fMRI stands for functional Magnetic Resonance Imaging (MRI), which is a technique that measures brain activation indirectly by using the magnetic properties of oxygen bound by hemoglobin is transported in the blood flow to replenish neurons with oxygen after neuronal activity has taken place. Thus, different levels of activation can be inferred in relation to cognitive tasks and/or stimulus presentation in a given experiment by comparing correspondent hemodynamic responses using BOLD measures (blood oxygen level dependent). A classic experimental paradigm in language research, for example, is to record activity in response to sentence stimuli compared to word sequence stimuli; the activity that results from this 'cognitive subtraction' is thought to reflect those operations that are specific to syntactic and semantic sentence building only (as opposed to simply accessing lexical information), and the neuroanatomical areas in which this activation is found are thought to be areas specifically recruited for those operations.(SOTO, 2014) 
where someone in the scanner was talking to someone outside of the scanner. We've tried many different things and some have been really successful and some haven't, because sometimes we could replicate the effect that we got the first time. And sometimes when we tried to replicate it the second time it wasn't there anymore, because there are so many different things that influence it and from some of the experiments we've done, we've genuinely learned something, and from others not so much.

A/M: Which kind of paradigms are most successful?

$\mathrm{K}$ : In my opinion, we learned a lot from the virtual reality experiments because there you do have a good balance between experimental control and you'll have a communicative context where people interact - a person and a virtual agent. If you have a research question that could be answered with that method, it can work quite well. In one paper, for example, we had people interacting with a virtual agent. ${ }^{5}$ We manipulated this virtual agent depending on facial features and how this agent behaved and spoke. We manipulated how the participant was going to evaluate this virtual agent in terms of: I feel really positive or I feel really negative or I feel sort of average towards this...

$\mathrm{A} / \mathrm{M}$ : Is that's the social perception you were mentioning in your articles?

$\mathrm{K}$ : Yes, that's the one in which the first author is Evelienn Heyselaar. We combined EEG ${ }^{6}$ and virtual reality, so we found that based on the EEG responses you're able to give most attention to someone that you evaluate average. You're able to give less attention to someone that you evaluate really positively or really negatively. That was a really strong and clear result, which also aligns very well with a lot of behavioral experiments we did. We feel confident that attention is probably a mechanism that drives a lot of these social effects, so there we feel like we hit the right balance between a controlled experiment and still having some sort of communicative interaction.

$\mathrm{A} / \mathrm{M}$ : What was the strangeness factor in that paradigm? How did you manipulate that?

\footnotetext{
5 Heyselaar, E., Hagoort, P., \& Segaert, K. (2016). How social opinion influences syntactic processing-An investigation using virtual reality. PLoS ONE, 12(4), Article e0174405.

6 In EEG, brain wave patters (i.e. their frequencies over time) are measured. Some methodologies analyze frequency modulations in continuous EEG data, other methodologies measure responses to stimuli. In language research, the latter methodology, Event Related Potential (ERP), has a long history since the early 1980s. ERP responses are averaged brain wave responses synchronized to the presentation of a stimuli, such as a written word, or phonological sound that is presented. Averaged responses usually follow a pattern that transcends different languages, modalities, but instead are thought to be a sort of brain signature of a given cognitive process. The N400, for example, is a much replicated response to words presented in isolation or in sentences, that occurs 400ms after stimulus presentation.54 (KUTAS; FEDERMEIER, 2011)
} 
$\mathrm{K}$ : It turns out that you can manipulate eyebrow movements and blinking rates and all sorts of things where you wonder is this going to have a huge effect? And then you get this super consistent effect on how you feel towards this avatar that you're interacting with, just based on eyebrow movements, blinking rate and speech.

Now we're trying to reflect on the topic of cooperation as a joint action. We're having loads of fun at the moment programming fun communicative games where you have two people who have a challenge, and they need to successfully communicate to complete it. We were inspired by this really funny computer game called "keep talking so nobody explodes". One person has to defuse a bomb and the other person has the bomb manual; the person defusing the bomb can't see manual, so they have to talk about these abstract things, like symbols, they see wires that need cutting, and they have to successfully cooperate and communicate to make sure the bomb doesn't explode. We're going have very free communication, we have no idea whether this is going work or not. Both participants are going wear EEG caps and we're going to look at oscillatory brain responses. ${ }^{7}$ Then, we will measure the connectivity between the two participants and see if these brain responses align more, that is, whether they synchronize if people communicate successfully.

A/M: There are lots of studies on that with music, aren't there? There was a study here in São Paulo about violinists playing together. ${ }^{8}$

$\mathrm{K}$ : There are some studies with a technique called fNIRS9, but it doesn't really tell you very well how the brain is working - not as well as with EEG. There are a lot of EEG studies with two participants that are doing nonverbal joint action tasks.o we're going to try and bring it to real verbal communication and see. I think we're going to have a lot of fun the next couple of years, but I

7 Oscillatory brain responses are the wave-like patterns recorded from neuronal activity. Alternation between negative and positive voltage reflects (post) synaptic activation, which is caused by differently charged environments between neurons through the exchange of neurochemical substances (i.e. neurotransmitters). In connectivity measures, the aim is to see whether brain waves synchronize (i.e. display similar frequencies), for example, in two different brain areas, or in two participants. The supposition is that synchronization of oscillatory brain responses indicate some sort of functional connectivity.

8 Vanzella, P., Balardin, J. B., Furucho, R. A., Zimeo Morais, G. A., Braun Janzen, T., Sammler, D., \& Sato, J. R. (2019). fNIRS Responses in Professional Violinists While Playing Duets: Evidence for Distinct Leader and Follower Roles at the Brain Level. Frontiers in psychology, 10, 164. https://doi.org/10.3389/fpsyg.2019.00164

9 fNIRS stands for functional Near-Infrared Spectroscopy (fNIR). It is similar to fMRI, in that it takes advantage of blood oxygenation levels in the brain, which vary as neurons increase oxygen demand as a result of engaging in activity thought to reflect cognitive processing. However, instead of the magnetic properties of hemoglobin, fNIR is able to generate functional neuroimages based on the absorption of near infrared light by the hemoglobin that binds oxygen. fNIRS is not as precise as fMRI in spatial resolution, but it has the advantage of being recorded on the scalp, similar to EEG, which leaves more freedom for participants to move or sit up. While temporal precision is better than fMRI, it is not as precise as EEG (SCARAPICCHIA et al., 2017). 
don't know if we'll be successful. I don't know whether we'll get it right, the balance between the experimental control and the naturalistic communication. We won't know until three, four years from now. It might be an enormous failure, or a huge success.

So, in these experiments, we are very much interested in looking at cooperation. Our first step is also to look at how empathy affects it. If you're talking about cooperation, this is a really obvious thing. We'll add a lot of empathy questionnaires and we'll see how that influences things.

A/M: What were some of the effects of the artificiality that you have in emulating these communicative settings?

$\mathrm{K}$ : It's a difficult question. I imagine it also depends on which experiment and whatever is relevant for the research questions Maybe you first need to know how it works in a very artificial context with just one person and then you can build from there. I mean, when I say all these other things have an influence on it, I mean they're going to modulate how it works or slightly impact on how it works, but I don't think you all of a sudden get a completely different mechanism. Syntactic priming is one of those things that people study all the time. There are a million syntactic priming experiments out there, and the vast majority of them are with one participant in a very controlled setting. What we know from all the syntactic priming experiments where you do have two participants and you do have a social context, is that you can slightly modulate the effect, but it's not like all of a sudden the effects appear or disappear.

A/M: We also noticed that you recently published a series of studies on aging and language processing? ${ }^{10}$ Why did you become interested in this topic, and what was it like for you to work with a different population than you were perhaps used to?

$\mathrm{K}$ : In the beginning, when I was a $\mathrm{PhD}$ student and a postdoc, I also only did research on young adults, 20 year-olds who come in, or psychology students who need credits for the course, so they have to come and do experiments. It wasn't until I got a little bit older myself and I started thinking about it. I suppose it goes back to the fact that a lot of my research is really driven by my curiosity of knowing how things work. I guess also, as I was getting a bit older, I started to reflect more about being less self-centered and about the society around me. We have this huge increase in people who

10 To cite just a few of the studies, Katrien talks about: Hardy, S., Segaert, K., Wheeldon, L. (PsyArXiv Preprint). Age-related disruption in the use of lexical information during sentence production, despite preserved syntactic planning. (can be accessed here: https://psyarxiv.com/xrbta ). Segaert, K., Lucas, S.J.E., Burley, C.V., Segaert, P., Milner, A.E., Ryan, M., Wheeldon, L. (2018) Higher physical fitness levels are associated with less language decline in healthy ageing. Scientific Reports, 8:6715. doi: 10.1038/s41598-018-24972- 
are older, but what do we know about how they process language? I considered that there's a lot we know, but that there's also a lot we don't know. And so it was only six years ago, that I started doing aging research. It is very different to interact with older adults. They are less experienced at doing experiments, but they're also a lot more motivated. They really want to do well, they are very chatty, and they want to stay as long as possible, because they want to help you. They always want to know why you're doing the research. But older adults can get upset if they are not good at a task. They start to worry that maybe they're not good at it and other people are, and whether that means that maybe they're not doing well anymore, in terms of their cognitive health. So I learned I have to make sure that I explain things, that I frame things well, that I make sure I don't emphasize accuracy, I don't come up with tasks that they can't do easily. I program my tasks such that the tasks don't end automatically if the older adults make too many mistakes, because you don't want to upset people. You don't want to make a participant feel that their cognitive health is declining just because they can't do a really stupid experiment in a laboratory. So that's something that I've learned to consider that I never considered before.

$\mathrm{A} / \mathrm{M}$ : What is your opinion about the importance of diversity in participants, for example, in terms of socio-economic backgrounds?

K: I think it's hugely important, I mean, we can come up with the most amazing theory of how we speak or produce language or retrieve words or whatever, if it doesn't apply to the population, what's the point? If it only applies to first-year psychology students, what have we really learned? And [this is especially important now that] we know that older adults process language differently. So I believe theories need to be able to account for that, and especially nowadays aging research is becoming more relevant than it ever was. Just because older adults are a bigger part of the population now than they used to be, especially in Europe ${ }^{11}$.

A/M: What have you found? Can you tell us something already?

$\mathrm{K}$ : Loads of things. I suppose a lot of people still think that in terms of comprehending language for older adults things don't change much, but in terms of producing language you do see a decline with aging. My research doesn't confirm that at all. There is also decline in terms of comprehending language. With regards to behavior, there's also huge individual variability: one 65-year-old is going

11 This is not so much the case in Brazil, where the median age is 33.3 (CIA world factbook, 2018 estimate), although there is a tendency towards a larger percentage of the population to be over $30,57,1 \%$-in 2018 , compared to $52,4 \%$ in 2012 (ibge.gov.br). In the UK, for example, 62.5\% was over 30 in 2011, and percentages are even higher in other European countries, such as Germany (ons.gov.uk). 
to be completely different from another 65-year-old. One could perform at a level of a 30-year-old while the other could perform maybe at the level of what you would imagine a 90 -year-old would be. In terms of aging research, there's a lot of variability that has nothing to do with age. It's a lot more about how you age. That includes things such as genetics, of course, but it also includes a host of lifestyle things, for example, how much you exercise, how much you stay mentally active, your diet, how well you sleep. The list is endless.

A/M: So also could you maybe conclude that these variables modulate the effects to a higher extent in older people than in younger people?

K: Yes! Because they have such a huge impact on how the aging process makes cognition decline. There's such individual variability in how people age. The individual variability in just about any task in a group of 60-year-olds is much more than the individual variability in a group of 20 -year-olds. As you age, there's a huge decline in every aspect of brain structure, so your brain needs to reorganize its functional processing, but how well your brain does that is very much dependent on all of these other factors. And that influences cognition, of course, which includes language for me.

$\mathrm{A} / \mathrm{M}$ : Since this is socially so relevant now, is that something you can get funding for relatively easily?

K: I can't get funding easily for anything! But the funding that I have gotten, let me think carefully, it was for aging research. So maybe that is a reflection of the fact that it is becoming more important. It was not something that was a huge thing to consider about 15 years ago, but now we really have to figure this out, because our society is changing.

A/M: And in terms of methodology, did you have questionnaires that you would use for younger people and then you just applied them to older people?

K: No. I feel I had to learn gradually, you can never just simply have an experiment you did on young people, do the same with older people and see what happens. It's never that simple because they need more time for things, and you want to measure language, not how fast they can [perform a task]. There are some things you have to take into account. For example, when you do a tip-of-the-tongue experiment where you measure how easily people can retrieve words, you can do that by giving people pictures or definitions of things to make them find words. If you devise an experiment for young people, you can ask them who is married to Brad Pitt. But a 70 year old doesn't know about that. They know about actors that were famous 50 years ago. Even the nature of your stimuli, they 
need to be different, because they need to be relevant.

A/M: We read that you have a paper that shows that older people have to be fit in order to have better cognitive processing. How do you measure that a person is fit? With a questionnaire?

$\mathrm{K}$ : Not a questionnaire. I am not scared of interdisciplinary things. I really enjoy working with people who know things that I don't. And for this [study] I worked with people who are exercise physiologists; they measure how fit people are. So basically they put people on a stationary exercise bike, which gets incrementally more difficult. The resistance gets bigger on the exercise bike, and they have to exercise, while we measured oxygen uptake. So they were wearing some sort of masks, and that measured oxygen uptake, while they were exercising. And they had to keep exercising until they reached $80 \%$ of their maximal heart rates because it would be unsafe to go further than that. From that you can derive a super objective measure of how fit someone is. If you go to a fitness center right now and they want to devise an exercise plan for you, that's what they would do. I believe it's really important to view being a researcher as something that is really interactive and to not be scared by things you don't know because that's the whole point of being a researcher, isn't it?

$\mathrm{A} / \mathrm{M}$ : The next question is related to this topic of interdisciplinarity. In terms of methodology, there's such great technology out there. But at the same time it's limiting, perhaps? Because the experimental environment restricts how natural participants can act, wouldn't you agree?

$\mathrm{K}$ : One of the biggest challenges is that language comprehension is a lot easier to study than language production. That's an issue of experimental control first. Because if you study language comprehension, you make people listen or read. You have full experimental control. If you study language production, you have to find intelligent tasks to make people produce language, but then in a way that you want them to, so that you can do something with the data. So it's an issue of devising good tasks, but it's also an issue of the actual neuroimaging methodology because basically for every single neural imaging methodology, when people are speaking, your signal gets incredibly affected and really really messy. So with fMRI, which is all about measuring blood flow in the brain, you're lying in an MRI scanner, if you're speaking, you're moving not just your jaw but also your head. But if your head is moving one millimeter, this ruins your signal, and because you're speaking, you have, what they call susceptibility artifacts, which is basically air. Air is coming out of your mouth when you're speaking. Speaking also messes up the signal for EEG, and for MEG as well. Speaking means movement. You're measuring electrical activity here [points to temples], and the electrical activity that you pick up is a lot weaker than the noise that is coming from your jaw and your muscles. The 
muscle artifacts are huge and your electrical signal because of language processing is very small. So it's an issue of tasks and an issue of the neuro imaging methodology. Production's really hard.

Again, it's about finding people who can help you. When we did production research in the MRI scanner, we worked together with people who were MRI physicists. Now I'm trying to do production with EEG and I work together with someone who's really strong in MEG methodology and has been for many years. I could never figure this out on my own.

A/M: How do you view your position as a researcher coming from humanities in a highly interdisciplinary field in which statistics, technology, computation and biology are combined into one? Is it difficult to understand all these fields?

$\mathrm{K}$ : I try to just constantly remind myself that it's not my responsibility to know all of these things. As much as I can, I feel I have to be strong in terms of research design, and statistics, also I have to know the literature, so that I can ask relevant research questions, but it's not part of my job to know the details of every single neuro imaging methodology. I need to know some of it and then find someone to help me. It's true statistics are important and I think that that is an advantage I have as a psychologist. If you do an undergraduate and a master's in psychology, it means years and years of training in statistics. So sure, statistics are challenging in a sense that you also need to keep updating your knowledge because things change. I'm not sure I see it as a limiting factor or something that makes things harder. I guess I see it more as an opportunity than a constraint, because there's so much that's possible. But then, I'm privileged of course because I have always worked in a place with very intelligent colleagues. The most important thing is to surround yourself with colleagues and to see it as something that's collaborative. You need to have good working relationships with people. Help each other out.

A/M: It's also a matter of infrastructure perhaps? I don't know what you've noticed about Brazil, [Katrien has visited Brazil several times] for example.

K: Yes, I know. That's why I said I feel that I'm very lucky. When I went to Florianópolis and Mailce [Mailce Borges Mota, who is a full professor at UFSC] wanted to do EEG. So we helped her set up the lab and showed her how to collect data. If you don't have people who can help you, you can't get anywhere. But you don't necessarily need to have people right there in the same place with you. You can have people anywhere in the world who can help you.

A/M: We're coming to the final few questions. This is a more general, but very relevant, 
question: how far has cognitive neuroscience come in terms of understanding the functional neural architecture in relation to language processing?

K: I don't know. For a technology that hasn't been around for that long, if you think about it, a lot of amazing stuff has happened. So much amazing stuff has happened in that small period of time, that in the next 50 years... I mean, by the time I am retired, I'm sure I will understand nothing of what the people are doing. But that is an optimistic thought, right? 40, 50 years from now we'll have learned so much, that I won't understand things. Now, we know about $1 \%$ of what goes on in the brain!

But it's also really exciting there are so many things we can do. You'll never run out of projects or research questions or experiments, I'm sure I can keep doing this until I retire.

I feel that language is sometimes the ugly duckling of cognition. You have you perception, attention and working memory, and it's all so cool - and the latest methods and this and that. Language is often like the ugly duckling, running a bit behind. But I think language is doing really well at the moment, and I think we should be really happy to be in this field

A/M: We saw your research has had some attention in the media. What is your view on popularizing neuro cognitive science especially with regards to language? What are the challenges of translating complicated scientific concepts procedures and analyses etc.

K: I don't think all research needs to be popularized, not all research needs to end up in the newspaper. But I am of the opinion that if you do do something that is relevant for people to know about, for example, if there are many reasons that exercising is good for you [i.e. it has a positive effect on language functioning], you do have a duty to spend some time communicating it. Because otherwise you're just a researcher in your office with a closed door. In the same way, it's your duty to talk to your colleagues, talk to people. Some studies you can really easily explain to your neighbor and other studies not so much. So I figure that if it's something that you want to talk to your neighbor about, it's really easy to talk to a journalist about it as well.

\section{REFERENCES}

KUTAS, Martha; FEDERMEIER, Kara. Thirty years and counting: finding meaning in the N400 component of the event-related brain potential (ERP). Annu Rev Psychol. 62:621-47, 2011. doi: 10.1146/annurev.psych.093008.131123. 
HARDY, Sophie M.; SEGAERT, Katrien; WHEELDON, Linda. (PsyArXiv Preprint). Age-related disruption in the use of lexical information during sentence production, despite preserved syntactic planning.

SCARAPICCHIA, Vanessa; BROWN, Cassandra; MAYO, Chantel; GAWRYLUK, Jodie R. Functional Magnetic Resonance Imaging and Functional Near-Infrared Spectroscopy: Insights from Combined Recording Studies. Frontiers in human neuroscience, 11, 419, 2017. https://doi. org/10.3389/fnhum.2017.00419

SEGAERT, Katrien; MENENTI, Laura; WEBER, Kirsten; PETERSSON, Karl Magnus; HAGOORT, Peter. Shared syntax in language production and language comprehension - An fMRI study. Cerebral Cortex, 22, p. 1662-1670, 2012, doi:10.1093/cercor/bhr249.

SEGAERT, Katrien; LUCAS, Sam .J.E.; BURLEY, Claire V.; SEGAERT, Pieter, MILNER, A.E.; RYAN, Matthew, WHEELDON, Laura. Higher physical fitness levels are associated with less language decline in healthy ageing. Scientific Reports, 8:6715. doi: 10.1038/s41598-018-24972, 2018.

SOTO, Marije. ERP and fMRI evidence of compositional differences between linguistic computations for words and sentences Orientadora: Aniela Improta França. Coorientador: Aline Gesualdi Manhães. 2014. 185 f. Tese (Doutorado) - Programa de Pós-graduação em Linguística, Faculdade de Letras, Universidade Federal do Rio de Janeiro, 2014.

VANZELLA, Patrícia; BALARDIN, Joana B.; FURUCHO, Rogério A.; ZIMEO MORAIS, Guilherme Augusto; BRAUN JANZEN, Thenille; SAMMLER, Daniela; SATO, João R. fNIRS Responses in Professional Violinists While Playing Duets: Evidence for Distinct Leader and Follower Roles at the Brain Level. Frontiers in psychology, 10, 164. 2019. https://doi.org/10.3389/ fpsyg.2019.00164 